2016 - Volume: 17 Number: 5

Page: 974 - 983

DOI : $10.18038 /$ aubtda. 265939

Received: 12 November 2016

Revised: 05 December 2016

Accepted: 08 December 2016

\title{
SYNTHESIS AND CHARACTERIZATION STUDIES OF A SERIES OF $N$-VINYL IMIDAZOLE-BASED HYDROGEL
}

\author{
Bilge ERDEM * \\ Department of Chemistry, Faculty of Science, Anadolu University, Eskişehir, Turkey
}

\begin{abstract}
In this study, poly[( $N$-vinyl imidazole)-co-(2-dimethylaminoethyl methacrylate)] hydrogels with various mole percentages of monomers were prepared by free radical solution polymerization in aqueous media. $N, N^{\prime}$-methylenebisacrylamide and 2,2'azobisisobutyronitrile were used as cross-linker and initiator, respectively. A Fourier transform infrared spectrophotometer, scanning electron microscope and thermogravimetric analyzer were used for the characterization of the hydrogels. The swelling behavior of the hydrogels in aqueous solution was investigated at $\mathrm{pH} 6.0$ and $25^{\circ} \mathrm{C}$. The results showed that swelling characteristics were affected by the 2-dimethylaminoethyl methacrylate content of the copolymeric hydrogel. The swelling degree of hydrogels increased from $4.2 \mathrm{~g} \mathrm{~g}^{-1}$ to $25.4 \mathrm{~g} \mathrm{~g}^{-1}$ by increasing the 2-dimethylaminoethyl methacrylate concentration from 0 to $15 \%$ with respect to the total moles of the monomers.
\end{abstract}

Keywords: $N$-vinyl imidazole, 2-Dimethylaminoethyl methacrylate, Copolymer, Hydrogel, Swelling

\section{INTRODUCTION}

Hydrogels are hydrophilic polymers that have three dimensional cross-linked networks. They do not dissolve in water, but they can swell up a great deal by absorbing water in aqueous solutions. Hydrogels are sensitive to heat, $\mathrm{pH}$, ionic strength, electric and magnetic fields, and may exhibit dramatic and reversible volume changes under these effects. Due to their excellent characteristics, hydrogels have attracted researchers' attention and exhibit potential applications in many fields from agriculture to medicine [1-9]. One of the most important factors determining the properties and applications of a hydrogel is its water absorption characteristics. The swelling behavior of hydrogels is related to various parameters such as the equilibrium degree of swelling, the diffusion parameters and the cross-linker content [10-13].

Although poly $(N$-vinyl imidazole) (p-VIm) hydrogels are neutral, the imidazole groups on the polymeric backbone have weak base character. Hence, p-VIm hydrogels exhibit reversible volume changes depending on the $\mathrm{pH}$ values of the aqueous solution because they can be easily protonated in acidic solutions [14]. $N$-vinyl imidazole (VIm) based hydrogels have attracted considerable attention. These kinds of hydrogels are frequently used as a protein carrier [15], a membrane for the anion exchange processes [16] and an adsorbent to remove some heavy metals from aqueous solutions [17-19].

To prepare new polymeric materials with special properties and expand the range of $\mathrm{p}$-VIm use, some works have been carried out on the synthesis of various VIm-based hydrogels. Although several groups of VIm-based hydrogels have been synthesized and characterized, the interaction between 2dimethylaminoethyl methacrylate (DMA) and VIm has not been studied up to now. Pekel and Guven [19] synthesized poly $(N$-vinylimidazole- $c o$-maleic acid) hydrogel by $\gamma$-irradiation of a ternary systems composed of $N$-vinylimidazole/maleic acid/water. They also determined their adsorption capacity for $\mathrm{Cu}^{2+}, \mathrm{Co}^{2+}, \mathrm{Cd}^{2+}$ and $\mathrm{Pb}^{2+}$ ions. In another study, synthesis of various compositions and the swelling behavior of poly(acrylamide-co- $N$-vinylimidazole) hydrogels were investigated. The highest equilibrium swelling was obtained under basic conditions at high temperature [1]. Uzum and Karadag [20] prepared the ternary semi interpenetrating hydrogels with acrylamide, $N$-vinylimidazole and

*Corresponding Author: bilgee@anadolu.edu.tr 
poly(ethyleneglycol), and swelling experiments were performed in water at $25^{\circ} \mathrm{C}$. Their investigations revealed that the swelling degree was highly dependent on the chemical composition of the hydrogels and reached up to $4167 \%$. Feng et al. [21] grafted p-VIm-based branches onto polymeric chitosan chains for the selective adsorption of $\mathrm{Hg}^{2+}$ ions from the aqueous solution. This prepared hydrogel was found to exhibit good reusability in the adsorption process.

An effective adsorbent character is shown by p-VIm due to its high levels of swelling degree, particularly at low $\mathrm{pH}$ values. Since the efficiency of p-VIm decreases with increasing $\mathrm{pH}$ [22], it is important to produce VIm-based copolymers that can show significiant swelling properties especially when the $\mathrm{pH}$ is neutral. The main goal of this study is to obtain this kind of copolymeric hydrogel, and, in this sense, DMA with a pKa value of approximately 8.1 is a proper monomer. VIm-based copolymeric hydrogels containing different percentages of DMA were prepared by free radical solution polymerization in aqueous solution in the presence of $N, N^{\prime}$-methylenebisacrylamide (BAAm) and 2,2'-azobisisobutyronitrile (AIBN) as a cross-linking agent and initiator, respectively. The swelling properties of the hydrogels were investigated at a $\mathrm{pH}$ of 6.0 to demonstrate their swelling characteristics at nearly neutral media for aqueous solutions. Swelling curves were obtained for the copolymeric hydrogels, and the kinetic parameters were calculated from these curves.

\section{EXPERIMENTAL}

\subsection{Materials}

$N$-vinyl imidazole, $N, N^{\prime}$-methylenebisacrylamide, 2,2'-azobisisobutyronitrile, 2-dimethylaminoethyl methacrylate and potassium bromide were purchased from Sigma-Aldrich (USA).

\subsection{Preparation of Hydrogels}

The p-VIm hydrogel was prepared according to existing literature [22]. To synthesize the copolymer containing $1 \%$ mole percentage of DMA (denoted by p-VIm-co-DMA_1), $20 \mathrm{mg}$ of AIBN was dissolved in $20 \mathrm{ml}$ of VIm, $0.51 \mathrm{~g}$ of BAAm and $0.45 \mathrm{ml}$ DMA were added to this solution with $50 \mathrm{ml}$ of distilled water. This mixture was immersed in a water bath at $80^{\circ} \mathrm{C}$ to be polymerized for 2 hours. The resulting hydrogel was left in deionized water for 24 hours and then dried in a vacuum oven at $60^{\circ} \mathrm{C}$. Copolymeric hydrogels containing mole percentages of 2.5, 5, 10, and 15\% DMA (p-VIm-co-DMA_2.5, p-VIm-coDMA_5, p-VIm-co-DMA_10 and p-VIm-co-DMA_15, respectively) were prepared using the same procedure used for the p-VIm hydrogel. The possible chemical structure of the copolymeric hydrogels is given in Figure 1. The abbreviations used in this study and their explanations are listed in Table 1.

Table 1. The list of abbreviations

\begin{tabular}{ll}
\hline Abbreviation & Explanation \\
\hline AIBN & 2,2'-azobisisobutyronitrile \\
DMA & 2-dimethylaminoethyl methacrylate \\
p-VIm-co-DMA_1 & Copolymer containing mole percentage of 1\% DMA \\
p-VIm-co-DMA_2.5 & Copolymer containing mole percentage of 2.5\% DMA \\
p-VIm-co-DMA_5 & Copolymer containing mole percentage of 5\% DMA \\
p-VIm-co-DMA_10 & Copolymer containing mole percentage of 10\% DMA \\
p-VIm-co-DMA_15 & Copolymer containing mole percentage of 15\% DMA \\
FTIR & Fourier transform infrared \\
VIm & $N$-vinyl imidazole \\
BAAm & $N, N^{\prime}$-methylenebisacrylamide \\
p-VIm & Poly(N-vinyl imidazole) \\
SEM & Scanning electron microscope \\
TG & Thermogravimetric \\
$S\left(\mathrm{~g} \mathrm{~g}^{-1}\right)$ & The swelling degree \\
$S_{\infty}$ & The swelling degree at an equilibrium state \\
$S_{t}$ & The swelling degree at time $t$ \\
$k_{s}$ & The swelling rate constant \\
$W_{d}(\mathrm{~g})$ & The weight of dry sample \\
$W_{s}(\mathrm{~g})$ & The weight of swollen sample \\
\hline &
\end{tabular}




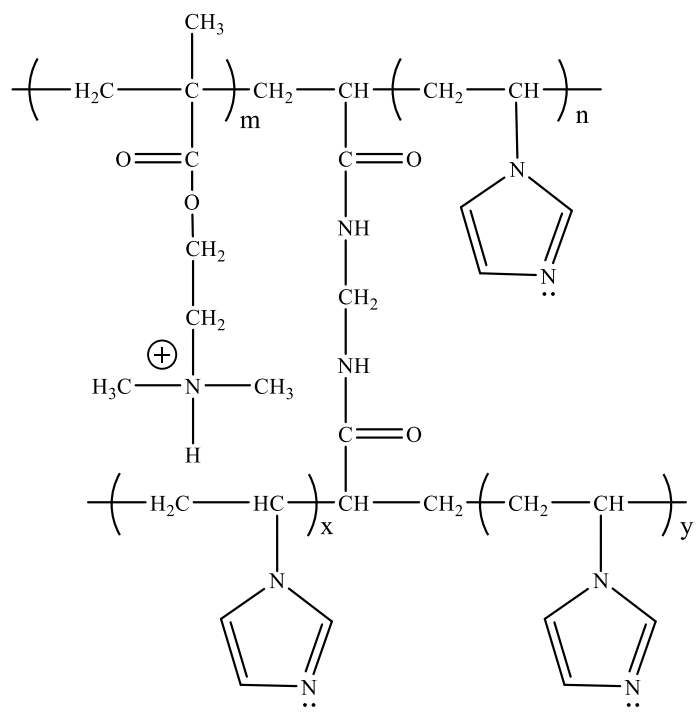

Figure 1. Schematic representation of the possible structure of copolymers in aqueous media at $\mathrm{pH} 6.0$

\subsection{Characterization of Hydrogels}

The Fourier transform infrared (FTIR) spectrophotometric analysis of the hydrogels was performed with a Perkin Elmer Spectrum 100 in the 4000 to $400 \mathrm{~cm}^{-1}$ range by preparing potassium bromide discs. A scanning electron microscope (SEM, Carl Zeiss Ultra Plus) was used to investigate the surface morphologies of the hydrogels after freeze drying (for 24 hours, at $-50^{\circ} \mathrm{C}$ and at $0.1 \mathrm{mbar}$ pressure, using a Christ/Alpha 1-4 freeze dryer) and gold coating processes. Thermogravimetric (TG) analyses of the hydrogels were done in a Nitrogen atmosphere (having a flow rate of $30 \mathrm{ml} / \mathrm{min}$ ) with a TG analyzer (TGA, Setaram Labsys) from 25 to $800^{\circ} \mathrm{C}$ at a heating rate of $10^{\circ} \mathrm{C} \mathrm{min}^{-1}$.

\subsection{Determination of Swelling Degree}

The swelling process of hydrogels was examined gravimetrically at $25^{\circ} \mathrm{C}$. A certain amount of dried hydrogel was immersed into deionized water (at $\mathrm{pH}$ 6.0) and the swollen gel was then removed from the swelling media at regular time intervals. After wiping away the excess water with a filter paper, the hydrogel was weighed and put back in the same media again. The swelling degree $(S)$ of the hydrogel was calculated using Eq. 1:

$$
S=\frac{W_{S}-W_{d}}{W_{d}}
$$

where $S\left(\mathrm{~g} \mathrm{~g}^{-1}\right)$ is the amount of absorbed water per gram of hydrogel, and $W_{S}(\mathrm{~g})$ and $W_{d}(\mathrm{~g})$ are the weights of the swollen and dry samples, respectively.

\section{RESULTS AND DISCUSSION}

\subsection{Characterization of Hydrogels}

FTIR spectra of p-VIm and p-VIm-co-DMA_15 hydrogels are shown in Figure 2. Characteristic bands for $\mathrm{p}$-VIm are observed at $3100 \mathrm{~cm}^{-1}$ (C-H ring stretching), $2940 \mathrm{~cm}^{-1}\left(\mathrm{C}-\mathrm{H}\right.$ and $\mathrm{CH}_{2}$ stretching on the main chain), $1650 \mathrm{~cm}^{-1}\left(\mathrm{C}=\mathrm{C}\right.$ ring stretching), $1500 \mathrm{~cm}^{-1}(\mathrm{C}-\mathrm{C}$ and $\mathrm{C}=\mathrm{N}$ ring stretching), 1280, 1230, 1085 and $915 \mathrm{~cm}^{-1}(\mathrm{C}-\mathrm{H}$ ring bending and $\mathrm{C}-\mathrm{N}$ ring stretching) [23]. In 
addition, the presence of $\mathrm{C}=\mathrm{O}$ stretching vibration band at $1720 \mathrm{~cm}^{-1}$ and asymmetric stretching vibration band of $\mathrm{C}-\mathrm{O}-\mathrm{C}$ at $1145 \mathrm{~cm}^{-1}$ indicates that the copolymer was successfully synthesized.

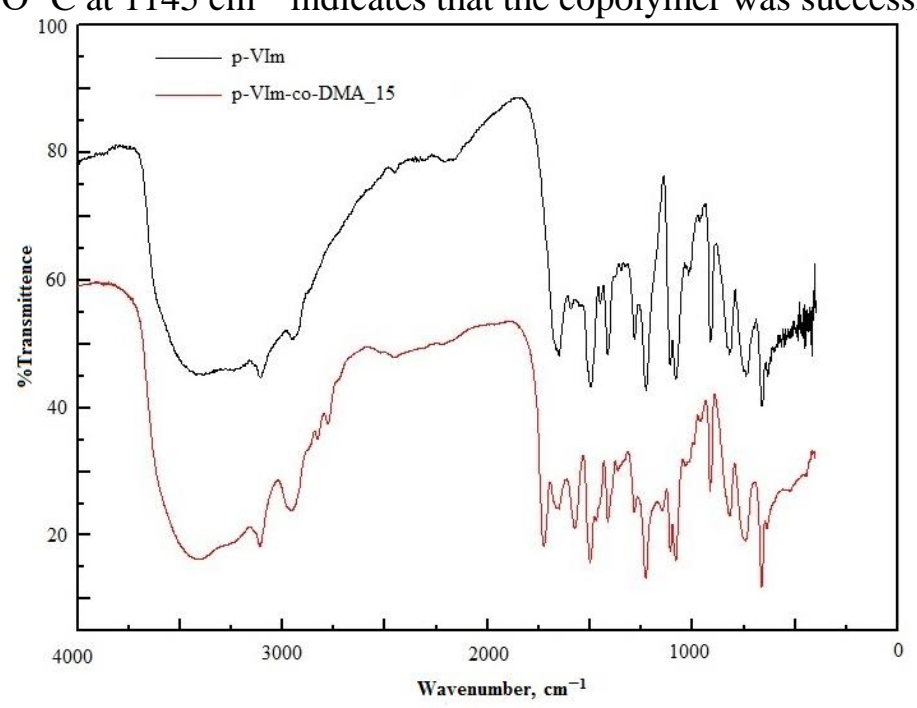

Figure 2. FTIR spectra of p-VIm and p-VIm-co-DMA_15

SEM images of the hydrogels (Figure 3 a-f) show that hydrogels have a very porous, spongy and leaflike morphology, which possibly causes increased surface area. It can be concluded that this kind of morphological structure would potentially bring easier and faster diffusion of water molecules into the polymeric network [24].
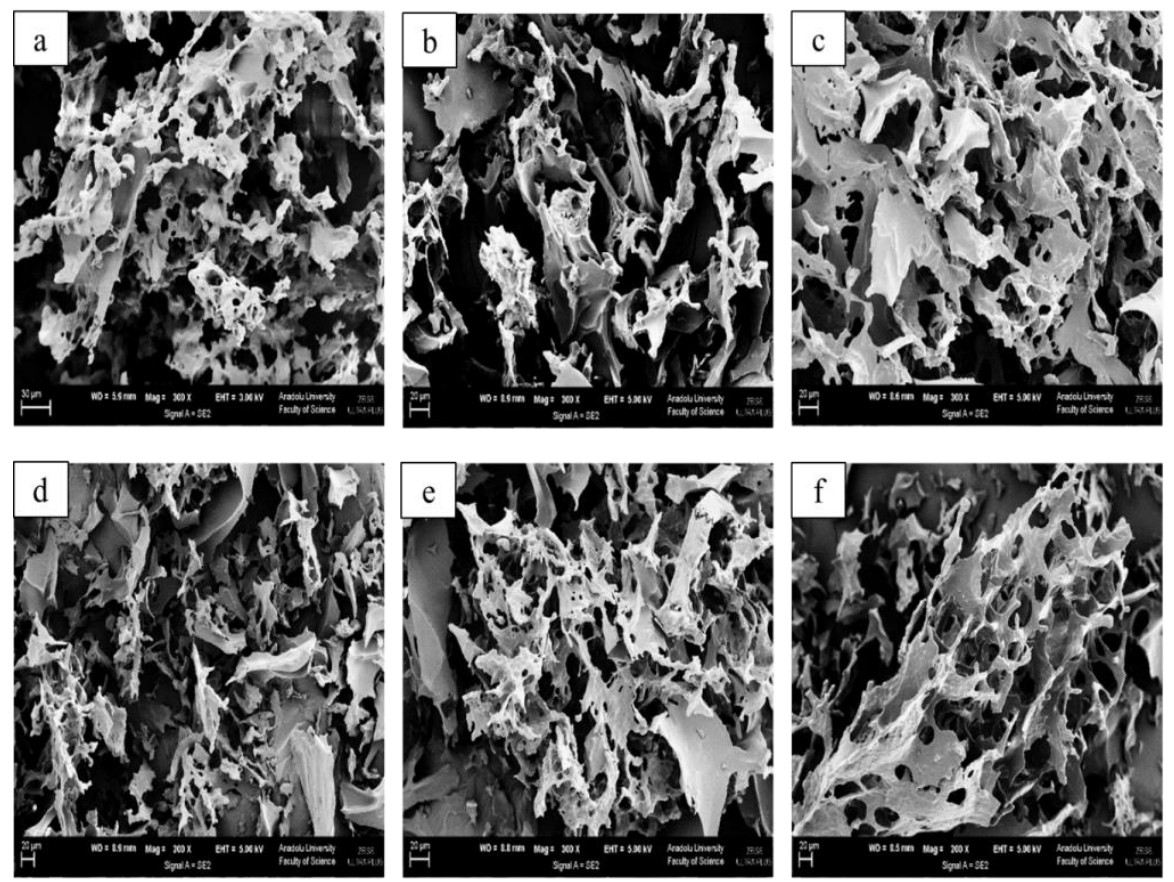

Figure 3. SEM images of (a) p-VIm, (b) p-VIm-co-DMA_1, (c) p-VIm-co-DMA_2.5, (d) p-VIm-coDMA_5, (e) p-VIm-co-DMA_10, (f) p-VIm-co-DMA_15

The TG curves of the hydrogels are shown in Figure 4 and the results are given in Table 2. As seen in Figure 4, there was one thermal decomposition step for p-VIm, while two steps were observed for copolymeric hydrogels. This two-step thermal decomposition process for copolymeric hydrogels may 
be a result of the decomposition of the two different kinds of moieties: DMA and VIm. The first weight loss steps of hydrogels (from 50 to $160^{\circ} \mathrm{C}$ ) can be attributed to the water loss and to volatile compounds adsorbed at their surfaces. For p-VIm, a weight loss is observed due to the decomposition of the polymeric networks in the temperature range from 310 to $480^{\circ} \mathrm{C}$ [22]. In contrast, the first decomposition step of the copolymeric hydrogels shifted to lower temperatures (from 150 to $330^{\circ} \mathrm{C}$ ). It was observed that as the DMA content in the polymeric matrix increases, the weight loss increases. The second decomposition step of the copolymeric hydrogels, which resulted in higher weight losses than those of first steps, were observed in the range from 300 to $530^{\circ} \mathrm{C}$ and can be ascribed to the decomposition of the VIm moieties of the polymeric backbone. The thermal stability of p-VIm is also found to be decreased considerably as a result of copolymerization.

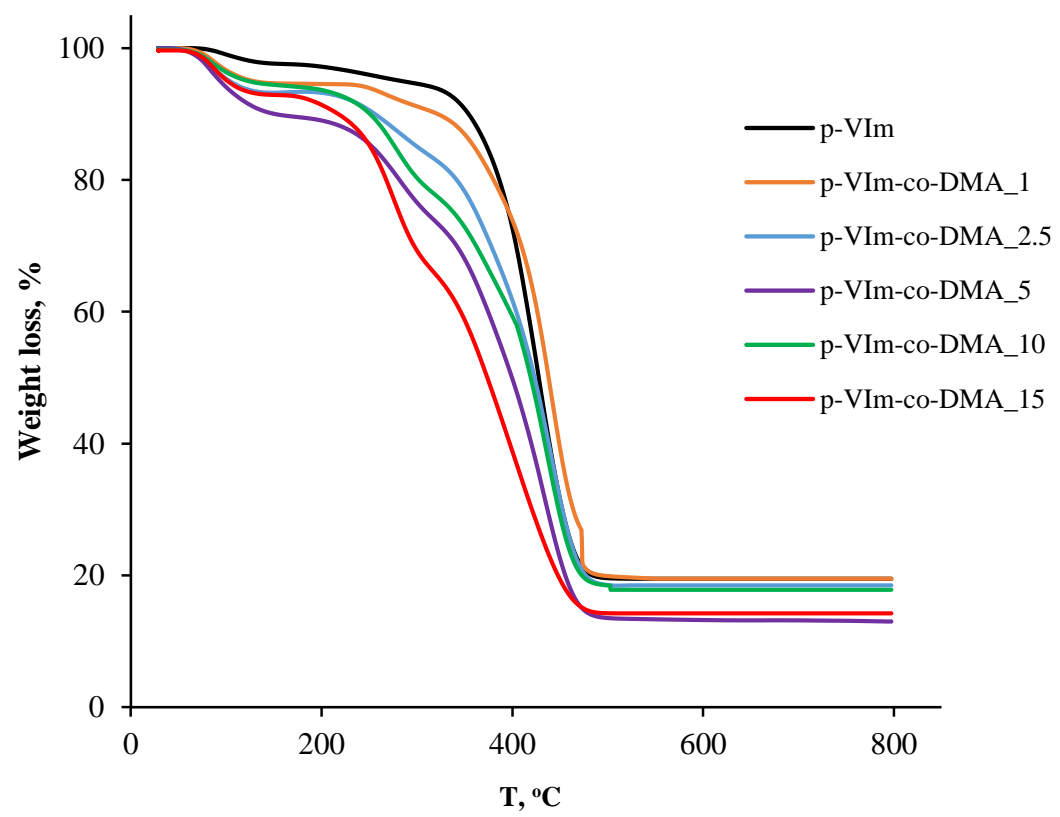

Figure 4. TG curves of the hydrogels

Table 2. The summary of TG analyses results

\begin{tabular}{|c|c|c|c|c|}
\hline Sample & Process & $\begin{array}{c}\text { Temperature range } \\
\left({ }^{\circ} \mathrm{C}\right)\end{array}$ & Weight loss (\%) & $\begin{array}{c}\text { Ash amount at } \\
800^{\circ} \mathrm{C}(\%)\end{array}$ \\
\hline \multirow[t]{2}{*}{$\mathrm{p}$-VIm } & $\begin{array}{l}\text { Losses of water and volatile } \\
\text { compounds }\end{array}$ & $80-140$ & 2.3 & \multirow[t]{2}{*}{$19.7[22]$} \\
\hline & Decomposition step & $310-480$ & 74.8 & \\
\hline \multirow{3}{*}{ p-VIm-co-DMA_1 } & $\begin{array}{l}\text { Losses of water and volatile } \\
\text { compounds }\end{array}$ & $60-140$ & 5.2 & \multirow{3}{*}{19.5} \\
\hline & First decomposition step & $235-300$ & 3.4 & \\
\hline & Second decomposition step & $300-510$ & 69.9 & \\
\hline \multirow{3}{*}{ p-VIm-co-DMA_2.5 } & $\begin{array}{l}\text { Losses of water and volatile } \\
\text { compounds }\end{array}$ & $55-140$ & 6.7 & \multirow{3}{*}{18.8} \\
\hline & First decomposition step & $200-300$ & 8.1 & \\
\hline & Second decomposition step & $300-515$ & 66.4 & \\
\hline \multirow{3}{*}{ p-VIm-co-DMA_5 } & $\begin{array}{l}\text { Losses of water and volatile } \\
\text { compounds }\end{array}$ & $50-140$ & 9.5 & \multirow{3}{*}{14.4} \\
\hline & First decomposition step & $150-300$ & 13.5 & \\
\hline & Second decomposition step & $300-515$ & 62.6 & \\
\hline \multirow{3}{*}{ p-VIm-co-DMA_10 } & $\begin{array}{l}\text { Losses of water and volatile } \\
\text { compounds }\end{array}$ & $50-165$ & 5.5 & \multirow{3}{*}{14.7} \\
\hline & First decomposition step & $175-330$ & 17.6 & \\
\hline & Second decomposition step & $330-530$ & 60.7 & \\
\hline p-VIm-co-DMA_15 & Losses of water and volatile & $55-140$ & 6.6 & 14.9 \\
\hline
\end{tabular}


Erdem / Anadolu Univ. J. of Sci. and Technology-A-Appl. Sci. and Eng. 17 (5) - 2016

\begin{tabular}{lcc}
\hline compounds & $175-325$ & 27.9 \\
First decomposition step & $325-500$ & 50.6 \\
\hline Second decomposition step & & \\
\hline
\end{tabular}

\subsection{Swelling Behavior in Aqueous Solution}

The swelling behavior of a hydrogel, which contains ionizable monomers such as VIm and DMA, can be affected by the nature of the polymer (i.e., the monomer composition and the content of crosslinking agent) and the environmental conditions such as $\mathrm{pH}$, temperature and ionic strength of the swelling media. It was expected that the presence of ionizable monomers in the polymeric structure would enhance the water retention capacity of the hydrogel. In this study, the effect of changing the molar ratio of DMA/VIm on the swelling degree of the hydrogels was investigated at $\mathrm{pH} 6.0$ and $25^{\circ} \mathrm{C}$; the results are depicted in Figure 5. As seen in Figure 5, hydrogels showed a rapid water uptake, and the swelling degree increased with the increasing content of DMA in the copolymer structure.

Cabot et al. [25] determined the $\mathrm{pK}_{\mathrm{a}}$ value of $\mathrm{p}$-VIm as 4.9. At $\mathrm{pH}$ 6.0, $\mathrm{p}$-VIm is neutral, while copolymeric hydrogels are positively charged because of the presence of DMA moieties whose pKa value is about 8.4 [26]. For this reason, the positive charge intensity on the polymer chains of copolymeric hydrogels increases with increasing DMA content. So, repulsive forces exist between the neighboring ammonium groups on the polymeric backbone. These forces enhance the diffusion of water into the polymeric lattice resulting in an increased degree of swelling [22].

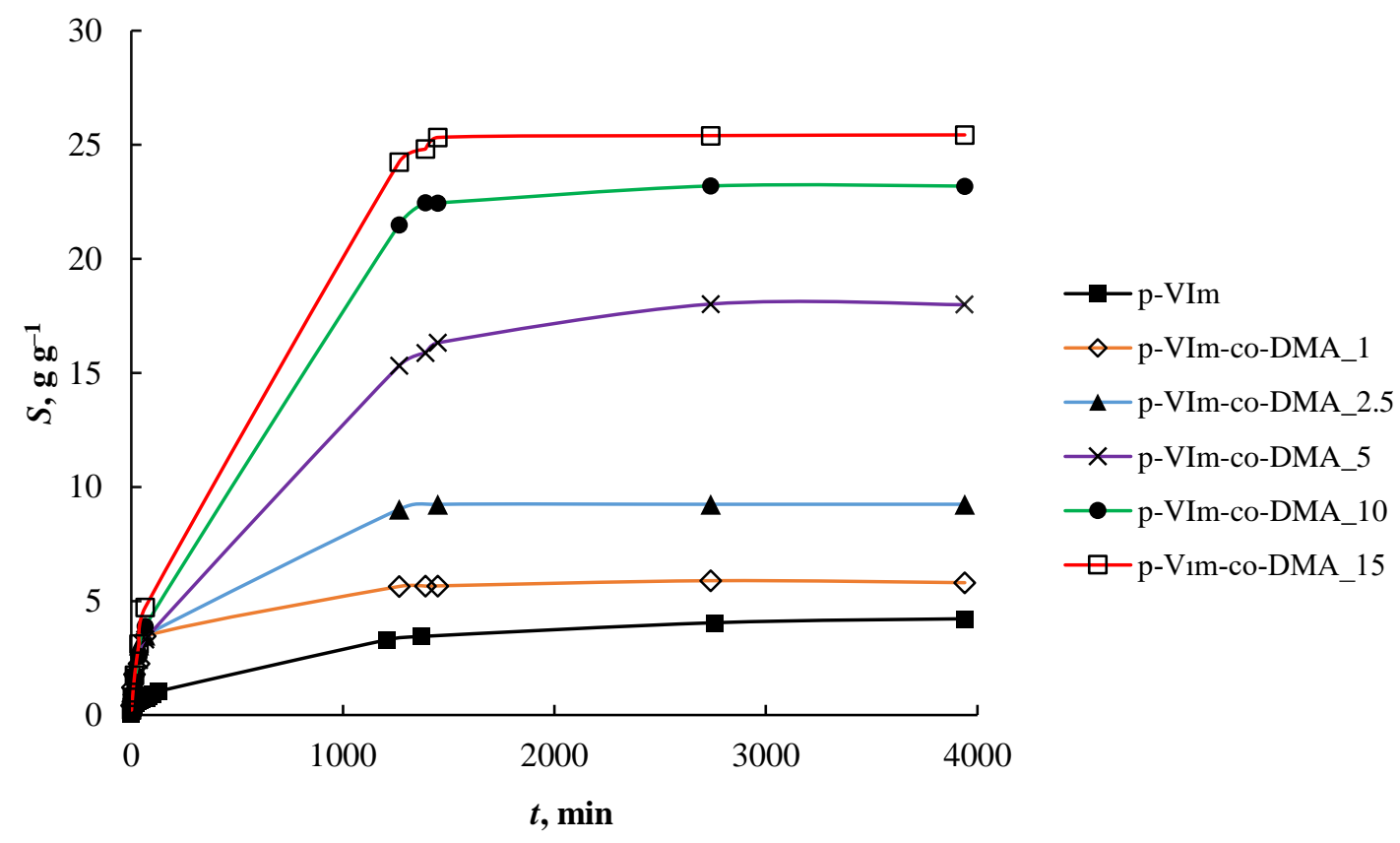

Figure 5. The swelling kinetic curves of the hydrogels in aqueous solution at $\mathrm{pH} 6.0$ and $25^{\circ} \mathrm{C}$

The experimental equilibrium swelling degrees of p-VIm, p-VIm-co-DMA_1, p-VIm-co-DMA_2.5, p-VIm-co-DMA_5, p-VIm-co-DMA_10 and p-VIm-co-DMA_15 are 4.20, 6.15, 9.88, 17.84, 23.07 and $25.64 \mathrm{~g} \mathrm{~g}^{-1}$, respectively (see Figure 5). The percentage swelling (experimental) of p-VIm-coDMA_15 increased up to $2564 \%$ while it was $420 \%$ for p-VIm. This means that the swelling degree increased by $610 \%$ with the presence of DMA. Uzum and Karadag [20] prepared some copolymeric hydrogels with acrylamide (AAm), $N$-vinylimidazole VIm and poly(ethyleneglycol) (PEG). They observed that the percentage swelling of AAm/VIm and AAm/VIm/PEG copolymeric hydrogels was higher than that of homopolymeric AAm hydrogel. In addition, a decrease in the percentage swelling 
of AAm/VIm/PEG hydrogels was seen when PEG was added to the hydrogel systems. With AAm/VIm (containing $80 \mathrm{mg}$ of $\mathrm{VIm}$ ) and AAm/VIm/PEG (containing $80 \mathrm{mg}$ of VIm), percentage swelling values were $4167 \%$ and $2574 \%$, respectively. Isik and Dogantekin [1] also synthesized a series of AAm/VIm copolymeric hydrogels and their hydrogels exhibited a percentage swelling of approximately $1400 \%$ at $\mathrm{pH} 5$ and $25^{\circ} \mathrm{C}$ and $1600 \%$ at $\mathrm{pH} 11$ and $25^{\circ} \mathrm{C}$. When the results obtained in this study with p-VIm-co-DMA_15 and p-VIm-co-DMA_10 at pH 6.0 (corresponding to percentage swelling of $2564 \%$ and $2307 \%$, respectively) are compared with those of the AAm/VIm series, it can be clearly said that VIm/DMA hydrogels demonstrated better swelling performance. Moreover, in the study of Pekel and Guven [19], a percentage swelling of $450 \%$ was obtained with VIm/MA (maleic acid) containing $5.82 \%(\mathrm{w} / \mathrm{w}) \mathrm{MA}$ at a $\mathrm{pH}$ of 6.0 .

To test the swelling rate, the swelling process of the hydrogels was evaluated using Schott's secondorder swelling kinetics model [27]. This model is expressed by Eq. 2:

$\frac{d S}{d t}=k_{S}\left(S_{\infty}-S_{t}\right)^{2}$

where, $k_{s}, S_{\infty}$ and $S_{t}$ denote the swelling rate constant, and the swelling degree at a state of equilibrium and at time $t$, respectively. The integration of Eq. 2 gives the following equation (Eq. 3):

$\frac{t}{s}=A+B t$

The constants $B=1 / S_{\infty}$ and $A=1 / k_{S} S_{\infty}^{2}\left(=1 /(d S / d t)_{0}=1 / r_{0}\right)$ can be calculated from the slope and intercept of Eq. 3. The plots of $t / S$ versus $t$ (Figure 6) show a good straight linear regression (with high $\mathrm{R}^{2}$ values), indicating that the swelling process of the hydrogels followed Schott's second-order swelling model. The values of the kinetic parameters $k_{s}, S_{\infty}$ and $r_{0}$ calculated from the slopes and intercepts, are tabulated in Table 3. It was shown that the swelling rate of the hydrogels was significantly influenced by the chemical composition of the structure, and that the values of $r_{0}$ increased with increasing DMA content in the copolymeric hydrogels. Furthermore, $S_{\infty}$ values of the hydrogels were also increased up to a DMA content of $15 \%$. These values are also similar to those of the experimental ones, suggesting that the kinetic model is in agreement with the swelling experiments. Higher swelling degree and enhanced swelling rate of the hydrogels with increasing content of DMA in the gel matrix are remarkable results. 


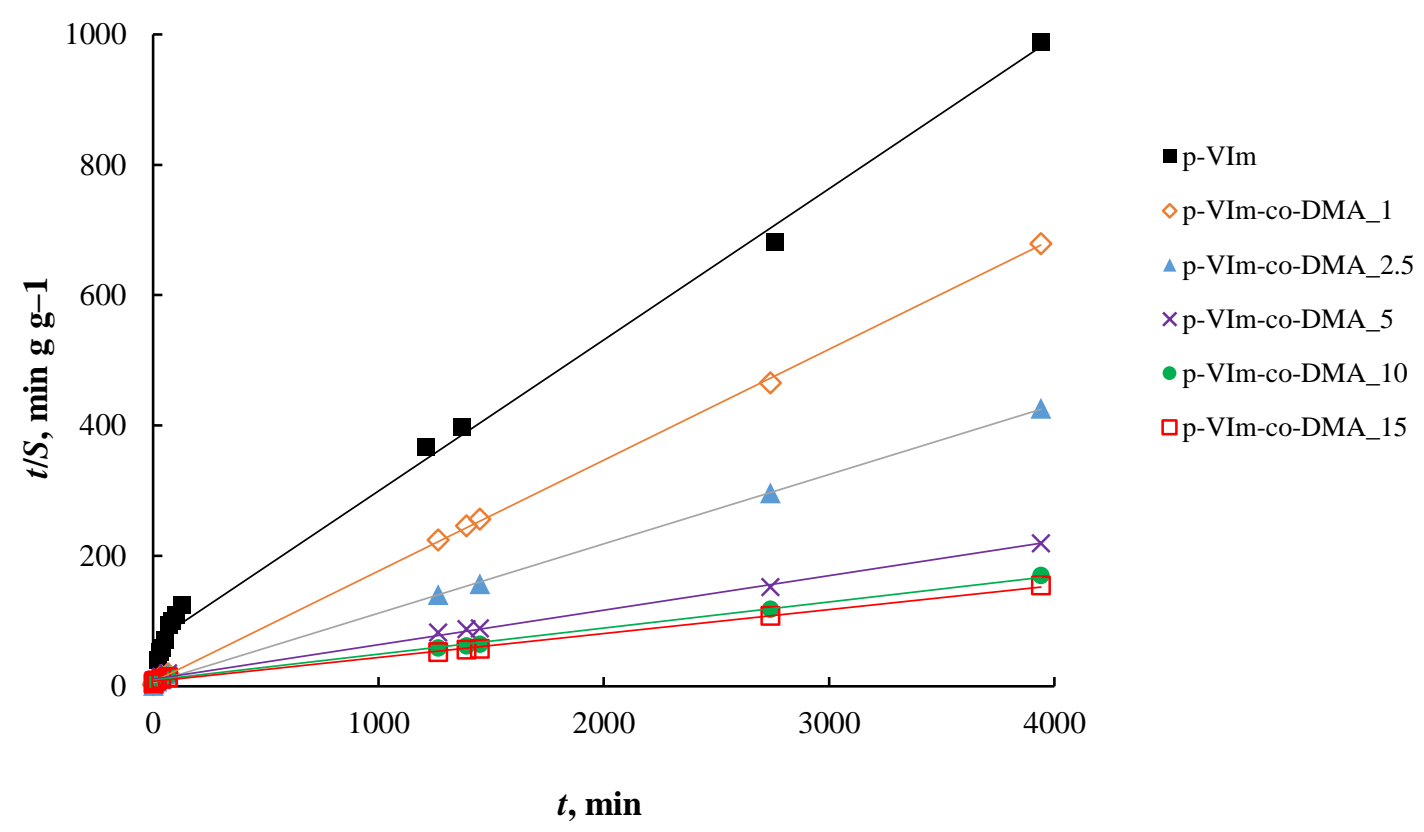

Figure 6. $t / S$ versus $t$ curves of hydrogels in aqueous solution at $\mathrm{pH} 6.0$ and $25^{\circ} \mathrm{C}$

Table 3. Swelling kinetic parameters of the hydrogels

\begin{tabular}{lcccc}
\hline Hydrogel & $\mathbf{R}^{\mathbf{2}}$ & $\boldsymbol{S}_{\infty}$ & $\boldsymbol{r}_{\mathbf{0}}$ & $\boldsymbol{k}_{\boldsymbol{s}}$ \\
\hline p-VIm & 0.9901 & 4.11 & 0.0177 & 0.00113 \\
p-VIm-co-DMA_1 & 0.9997 & 6.08 & 0.1508 & 0.00167 \\
p-VIm-co-DMA_2.5 & 0.9996 & 9.63 & 0.1817 & 0.00215 \\
p-VIm-co-DMA_5 & 0.9996 & 17.96 & 0.1984 & 0.00334 \\
p-VIm-co-DMA_10 & 0.9993 & 23.15 & 0.2234 & 0.00388 \\
p-VIm-co-DMA_15 & 0.9991 & 25.51 & 0.2689 & 0.00437 \\
\hline
\end{tabular}

\section{CONCLUSIONS}

In this study, p-VIm-based copolymeric hydrogels were synthesized at five different initial molar ratios via free radical solution polymerization in aqueous media, and characterization studies of them were carried out. FTIR, SEM and TGA were used for the structural, morphological and thermal characterization. The swelling behavior of the copolymers was also investigated. The following conclusions can be drawn:

- The additional bands $\left(\mathrm{C}=\mathrm{O}\right.$ stretching at $1720 \mathrm{~cm}^{-1}$ and asymmetric stretching of $\mathrm{C}-\mathrm{O}-\mathrm{C}$ at $1145 \mathrm{~cm}^{-1}$ ) in the FTIR spectrum of p-VIm-co-DMA_15 confirm that the copolymer was successfully synthesized.

- $\quad$ All hydrogels have a spongy and porous morphology.

- $\quad$-VIm was thermally more stable than copolymeric analogues. p-VIm showed one thermal decomposition step, while copolymeric hydrogels displayed two steps.

- The swelling degree increased with increasing DMA content in the hydrogels. It was observed that this value reached $25.64 \mathrm{~g} \mathrm{~g}^{-1}$ (experimental) with p-VIm-co-DMA_15 at $\mathrm{pH} 6.0$ and $25^{\circ} \mathrm{C}$ meaning that the swelling degree increased by $610 \%$ compared to that of $\mathrm{p}-\overline{\mathrm{V}} \mathrm{Im}$.

- $\quad$ The swelling kinetics of the hydrogels were fitted to the Schott's second-order swelling kinetic model with high linear regression values. The $S_{\infty}$ values increased up to $25.51 \mathrm{~g} \mathrm{~g}^{-1}$ with the content of $15 \%$ DMA. $r_{0}$ and $k_{s}$ values also increased with increasing DMA content in the hydrogels. 
- Improved swelling degree and kinetics even at neutral $\mathrm{pH}$ values revealed that these type of VIm-based hydrogels could be useful for various applications involving the removal of some contaminants such as heavy metal ions, dyes and some organic pollutants from wastewater by adsorption.

\section{REFERENCES}

[1] Isik B, Dogantekin B. Swelling behavior of poly(acrylamide-co-N-vinylimidazole) hydrogels under different environment conditions. J Appl Polym Sci 2005; 96: 1783-1788.

[2] Brannon-Peppas L, Peppas NA. Solute and penetrant diffusion in swellable polymers. IX. The mechanisms of drug release from $\mathrm{pH}$-sensitive swelling-controlled systems. J Control Release 1989; 8: $267-274$.

[3] Vazquez B, Gurruchaga M, Goni I, Narvarte E, Roman JS. A pH-sensitive hydrogel based on poly(ethoxy triethylene glycol monomethacrylate). Polymer 1995; 36: 3327-3333.

[4] Yu H, Grainger DW. Amphiphilic thermosensitive N-Isopropylacrylamide terpolymer hydrogels prepared by micellar polymerization in aqueous media. Macromolecules 1994; 27: 4554-4560.

[5] Eisenberg SR, Grodzinsky AJ. Electrically modulated membrane-permeability. J Membrane Sci 1984; 19: 173-194.

[6] Siegel RA, Firestone BA. pH-dependent equilibrium swelling properties of hydrophobic polyelectrolyte copolymer gels. Macromolecules 1988; 21: 3254-3259.

[7] Zhang XZ, Yang YY, Wang FJ, Chung, TS. Thermosensitive poly(N-isopropylacrylamide-coacrylic acid) hydrogels with expanded network structures and improved oscillating swellingdeswelling properties. Langmuir 2002; 18: 2013-2018.

[8] Lee KY, Mooney DJ. Hydrogels for tissue engineering. Chem Rev 2001; 101: 1869-1879.

[9] Discher DE, Mooney DJ, Zandstra PW. Growth factors, matrices, and forces combine and control stem cells. Science 2009; 324: 1673-1677.

[10] Tomic SL, Suljovrujic EH, Filipovic JM. Biocompatible and bioadhesive hydrogels based on 2hydroxyethyl methacrylate, monofunctional poly(alkylene glycol)s and itaconic acid. Polym Bull 2006; 57: 691-702.

[11] Yu J, Yang G, Li Y, Yang W, Gao J, Lu Q. Synthesis, characterization, and swelling behaviors of acrylic acid/carboxymethyl cellulose superabsorbent hydrogel by glow-discharge electrolysis plasma. Polym Eng Sci 2014; 54: 2310-2320.

[12] Tomic SL, Micic MM, Dobic SN, Filipovic JM, Suljovrujic EH. Smart poly(2-hydroxyethyl methacrylate/itaconic acid) hydrogels for biomedical application. Radiat Phys Chem 2010; 79: 643649.

[13] Hao J, Weiss RA. Mechanical behavior of hybrid hydrogels composed of a physical and a chemical network. Polymer 2013; 54: 2174-2182.

[14] Genc F, Uzun C, Guven O. Quaternized poly(1-vinylimidazole) hydrogel for anion adsorption. Polym Bull 2016; 73: 179-190. 
[15] Lemque R, Vidalmadjar C, Racine M, Piquion J, Sebille B. Anion-exchange chromatographic properties of alpha-lactalbumin eluted from quaternized polyvinylimidazole-study of the role of the polymer coating. J Chromatogr 1990; 553: 165-177.

[16] Jilge G, Sebille B, Vidalmadjar C, Lemque R, Unger KK. Optimization of fast protein separations on nonporous silica-based strong anion-exchangers. Chromatographia 1993; 37: 603-607.

[17] Molina MJ, Gomez-Anton MR, Rivas BL, Maturana HA, Pierola IF. Removal of $\mathrm{Hg}$ (II) from acid aqueous solutions by poly(N-vinylimidazole) hydrogel. J Appl Polym Sci 2001; 79: 1467-1475.

[18] Tu J, Zhou J, Wang C-F, Zhang Q, Chen S. Facile synthesis of N-vinylimidazole-based hydrogels via frontal polymerization and investigation of their performance on adsorption of copper ions. J Polym Sci Part A: Polym Chem 2010; 48: 4005-4012.

[19] Pekel N, Guven O. Spectroscopic and thermal studies of poly[(N-vinylimidazole)-co-(maleic acid)] hydrogel and its quaternized form. Polym Int 2008; 57: 637-643.

[20] Uzum OB, Karadag E. Swelling characterization of novel ternary semi-IPNs: acrylamide/1vinylimidazole/PEG hydrogels. Polym Adv Technol 2007; 18:483-489.

[21] Wang F, Zheng Y, Zhu Y, Wang A. Preparation of Chitosan-g-Poly(Vinylimidazole-co-2Acrylamido-2-Methyl Propane Sulfonic Acid) Granular Hydrogel for Selective Adsorption of $\mathrm{Hg}^{2+}$. Water Air Soil Pollut 2016; 227: 1-12.

[22] Erdem M, Dikisler O, Erdem B. Removal of Orange II from aqueous solutions using N-vinyl imidazole-based hydrogels as adsorbents. Chem Engin Commun 2016; 203: 1403-1412.

[23] Pekel N, Guven O. Synthesis and characterization of poly(N-vinyl imidazole) hydrogels crosslinked by gamma irradiation. Polym Int 2002; 51: 1404-1410.

[24] Li S, Liu X, Zou T, Xiao W. Removal of cationic dye from aqueous solution by a macroporous hydrophobically modified poly(acrylic acid-acrylamide) hydrogel with enhanced swelling and adsorption properties. Clean-Soil Air Water 2010; 38: 378-386.

[25] Cabot B, Deratani A, Foissy A. Adsorption of poly(vinylimidazoles) onto silica surfaces. Colloid Surface A 1998; 139: 287-297.

[26] van de Wetering P, Zuidam NJ, van Steenbergen MJ, van der Houwen OAGJ, Underberg WJM, Hennink WE. A Mechanistic study of the hydrolytic stability of poly(2-(dimethylamino)ethyl methacrylate. Macromolecules 1998; 31: 8063-8068.

[27] Serra L, Domenech J, Peppas NA. Drug transport mechanisms and release kinetics from molecularly designed poly(acrylic acid-g-ethylene glycol) hydrogels. Biomaterials 2006; 27: 54405451. 